\title{
Comparison of methods to quantify loss of hydraulic conductivity in Norway spruce
}

\author{
Peter HIETZ $^{1 *}$, Sabine RosNER ${ }^{1}$, Johannes SORZ $^{1}$, Stefan MAYR $^{2}$ \\ ${ }^{1}$ Institut für Botanik, Department für Integrative Biologie, Universität für Bodenkultur Wien, Gregor Mendel-Str. 33, 1180 Vienna, Austria \\ ${ }^{2}$ Institut für Botanik, Universität Innsbruck, Sternwartestr. 15, 6020 Innsbruck, Austria
}

(Received 6 November 2007; accepted 31 January 2008)

\begin{abstract}
-
- Percent loss of hydraulic conductivity (PLC) is an important measure in plant water relations, but the available methods differ and results have rarely been compared.

- We compared PLC measured in Norway spruce (Picea abies) by quantifying conductivity before and after removing emboli, either by flushing with high water pressure or by infiltration under a partial vacuum, with relative water loss and staining conductive xylem to test advantages and possible problems of commonly applied methods.

- Infiltration removed nearly all gas from sections of drought-stressed and unstressed twigs, and flushing and infiltration efficiently removed emboli. Infiltration appears less prone to producing clogged xylem elements than high pressure flushing. Relative water loss (RWL) and the proportion of xylem stained with phloxine B (PSX) was also highly correlated with PLC, the latter can be quantified by image analysis, and also shows the pattern of xylem dysfunction. Loss of conductivity was more common in the inner annual rings, in early wood within an annual ring, and in compression wood, though pattern differed substantially between branches.

- Advantages and potential problems of these methods are discussed and it is suggested that RWL or PSX may be used as proxy measures for PLC in species when the correlations have been established.
\end{abstract}

dye staining / percent loss of hydraulic conductivity / Picea abies / relative water content / xylem embolism

Résumé - Comparaison de méthodes de quantification des pertes de conductivité hydraulique chez l'épicéa.

- Le pourcentage de perte de conductivité hydraulique (PLC) est un paramètre important des relations hydriques des plantes, mais les méthodes de mesure disponibles diffèrent et les résultats ont rarement été comparés.

- Nous avons comparé des valeurs de perte de conductivité chez Picea abies obtenues en quantifiant la conductivité hydraulique avant et après suppression de l'embolie, soit par un flush d'eau sous haute pression soit par infiltration sous un vide partiel, avec les pertes relatives en eau et avec des méthodes de coloration du xylème conducteur coloré ; cette comparaison a permis de tester les avantages et les inconvénients potentiels des méthodes couramment utilisées.

- L'infiltration élimine presque tous les gaz des sections de petites branches, alors que de l'eau sous pression et l'infiltration suppriment l'embolie. L'infiltration paraît moins susceptible de provoquer une obstruction des éléments de xylème, qu'un flush à haute pression. Perte relative en eau (RWL) et proportion de xylème coloré avec de la phloxine B (PSX) étaient hautement corrélées avec la perte de conductivité. Une analyse d'image de xylème permet également de quantifier la perte de conductivité et de mettre en évidence la distribution spatiale des vaisseaux embolisés. La perte de conductivité a été très visible dans les cernes interne du tronc, dans le bois initial du cerne de l'année et dans le bois de compression, quoique les patrons diffèrent considérablement entre branches.

- Les avantages et les inconvénients potentiels de ces méthodes sont discutés et il est proposé que RWL ou PSX puissent être utilisées comme des estimateurs indirects de perte de conductivité une fois les corrélations établies pour chaque espèce.

colorant / pourcentage de perte de conductivité hydraulique / Picea abies / teneur relative en eau / embolisme du xylème

\section{INTRODUCTION}

Severe drought stress or freeze-thaw events can result in cavitations in conducting xylem elements, as a consequence of which emboli block the water path, reducing the hydraulic conductivity (Tyree and Zimmermann, 2002). Quantifying this loss of hydraulic conductivity, which is usually expressed as percent loss of conductivity (PLC), is important for many as-

*Corresponding author: peter.hietz@boku.ac.at pects of plant water relations. For instance, xylem vulnerability is analyzed by plotting PLC versus xylem water potential (e.g. Cochard, 1992; Hacke and Sperry, 2001), in situ PLC indicates that plants have suffered stress beyond the cavitation threshold (e.g. Sperry et al., 1994; Mayr et al., 2006), and a reduction of PLC indicates refilling of emboli (e.g. Cochard et al., 2001; Salleo et al., 1996).

Sperry et al. (1988) (see also Chiu and Ewers, 1993; Vogt, 2001) developed the standard method to quantify the loss of hydraulic conductivity by measuring the increase in 
conductivity after removal of enclosed air by repeated high pressure flushing. Alternatively, Sellin (1991) infiltrated wood under a vacuum, assuming that debarked branches up to $30 \mathrm{~mm}$ long and up to $17 \mathrm{~mm}$ thick were completely resaturated after $6 \mathrm{~h}$. More commonly, vacuum infiltration is applied for $48 \mathrm{~h}$ (Domec and Gartner, 2002). Infiltration has also been achieved by pressurizing submerged samples (Sperry, 1986), but this appears to be less efficient and does not work in all species. The Cryo-Sem technique (e.g. Cochard et al., 2000a; 2004) enables an analysis of the water content in frozen xylem samples. Dye staining was used for a qualitative estimation of embolised regions in stem cross sections (e.g. Mayr and Cochard, 2003; Sperry and Tyree, 1990). Vulnerability curves can also be measured using acoustic techniques (e.g. Kikuta et al., 2003; Lo Gullo and Salleo, 1991; Rosner et al., 2006), and recently a centrifuge technique for vulnerability analysis based on hydraulic measurements was tested (Cochard et al., 2005).

The standard hydraulic techniques require that samples can be restored to full $(100 \%)$ conductivity. This may be difficult, at least with some plants, and methods to restore full conductivity can differ in their effectiveness. Forcing water into the stem could also fill spaces that would be air-filled even in unstressed twigs at maximal conductivity (Gartner et al., 2004), for instance the pith, heartwood or inner sapwood with lower water content, resulting in unrealistic maximal conductivity and consequently exaggerated PLC. On the other hand, the maximum conductivity measured can be decreased, for instance by microbial growth or particulate matter (Sperry et al., 1988). Microbial growth is effectively suppressed by antimicrobial agents, but the blockage of pit membranes by particles often occurs when high pressure is applied to remove emboli, and preventing this is a test of the diligence of the laboratory procedures. Blockage of pores or of entire conducting elements is particularly likely in conifers, where the small dimensions of the tracheids means that the water needs to pass through a large number of pits. The special pit anatomy of conifers can also lead to an irreversible torus aspiration upon dehydration (Hacke et al., 2004; Hansmann et al., 2002; Petty, 1972). In consequence, restoration of full conductivity by flushing may not be possible and PLC be under-estimated. In addition, the resin present in most conifer wood may spread on the cut surface and clog the opened tracheids, so that measuring PLC in conifers can pose different problems from angiosperms. Problems with clogging are readily detected. If the conductivity decreases after successive applications of high pressure, which should remove emboli and thus increase conductivity, this indicates that vessels or tracheids are blocked by impurities (Sperry, 1986). Low saturation water content of twigs after flushing (twigs may float on water) also suggests that not all emboli have been removed.

We compared various estimates of PLC in spruce (Picea abies [L.] Karst.), a species where problems such as those above make alternative methods that avoid or reduce the blockage of tracheids desirable. These methods differ in their labor intensity and their potential problems, but have rarely been correlated (Domec and Gartner, 2002; Sellin, 1991), which makes comparing published results from different methods problematic. Because of the homogeneous anatomy of conifer wood, its conductivity only depends on one wood element (tracheids), as a consequence of which the outcome of different methods should mainly depend on the efficiency in removing emboli and avoiding blockage. We also hypothesize that PLC should be strongly correlated with relative water loss in conifer wood.

\section{MATERIALS AND METHODS}

Seventeen spruce trees, about 17 years old, had been grown in 1001 pots for three years. Some were subjected to severe drought in the summer of 2006 to induce loss of hydraulic conductivity. Between June and September first-order branches about 1-1.5 m long were cut, transported to the laboratory in plastic bags and separated into the following sections. A basal section of 7-10 cm was cut at the base and a distal one at a distance of about $50 \mathrm{~cm}$ for measurement of relative water loss (RWL). The remaining branch was submerged in water, first re-cut and the $20-25 \mathrm{~cm}$ adjacent to the base was cut into two central sections, from which the side-branches were separated also under water. The bark was stripped immediately from the proximal and distal section and fresh weight (FW) was determined. Then these sections were saturated in distilled and degassed water containing $0.005 \%$ (v/v) Micropur (Katadyn Produkte AG, Wallisellen, Switzerland) to prevent microbial growth under a partial vacuum (ca. $10 \mathrm{kPa}$ ) for at least $96 \mathrm{~h}$. After branches had sunk, saturation weight (SW) and dry weight (DW) after drying at $103{ }^{\circ} \mathrm{C}$ for three days were used to calculate relative water loss:

$$
\operatorname{RWL}(\%)=(1-(\mathrm{FW}-\mathrm{DW}) /(\mathrm{SW}-\mathrm{DW})) \cdot 100 .
$$

Surface water was removed from the two sections cut under water by blotting with absorptive cellulose tissue, sections were tightly wrapped in laboratory film (Parafilm, SPI Supplies, West Chester, PA, USA) and stored in plastic bags at $-18{ }^{\circ} \mathrm{C}$ until further preparation. Freeze-storage of Norway spruce sapwood samples for several weeks has no significant impact on specific hydraulic conductivity and vulnerability after thawing (Mayr et al., 2003; Rosner et al., 2006). To verify this and also to estimate the reproducibility of the method, 25 samples were analyzed for percent loss of conductivity (PLC) by infiltration under vacuum after staying frozen for one month, and compared with samples of the same sections frozen one to three months longer. The two central sections were used to analyze PLC by infiltration and staining, the other section served either as a backup for replications or was used to compare PLC by flushing and by infiltration, so that, apart from the RWL in distal and proximal sections, all measurements were made within ca. $15 \mathrm{~cm}$.

\subsection{Percent loss of conductivity by flushing (PLCf)}

Loss of hydraulic conductivity was quantified by measuring the increase in hydraulic conductivity after removal of xylem embolism by repeated high pressure flushes (Sperry et al., 1988). Analysis was done with a XYL'EM system (Embolism meter, Bronkhorst, Montigny les Cormeilles, France) which is based on a high resolution flow meter (Cochard et al., 2000b). Samples, 2 to $6 \mathrm{~cm}$ long and 4 to $8 \mathrm{~mm}$ in diameter, were prepared as described in Mayr et al. (2002). The bark was removed and the sample ends were re-cut several times 
under water. Measurement pressure was set to about $6 \mathrm{kPa}$ and continuously measured and corrected for with the XYL'EM pressure transducer. Flushing (at $120 \mathrm{kPa}$ ) and conductivity measurements were done with distilled, filtered $(0.22 \mu \mathrm{m})$ and degassed water containing $0.005 \%$ (v/v) Micropur. Samples were repeatedly flushed for 1520 min. until measurements showed no further increase in conductivity. Loss of conductivity in percent (PLCf) was calculated from the ratio of initial to maximal conductivity (Sperry et al., 1988).

\subsection{Percent loss of conductivity by saturation under partial vacuum (PLCv)}

The percent loss of conductivity was measured with a technique where the hydraulic conductivity is related to the conductivity after saturation in water under vacuum (Sellin, 1991). Branch samples were thawed and debarked under water. Segments of $5 \mathrm{~cm}$ length were sawed on a band saw and re-cut under water with microtome blades (Feather A-35, Feather Safety Razor Co. Ltd. Medical Division, Japan) to a length of $3 \mathrm{~cm}$. The adjacent $5 \mathrm{~cm}$ branch segment of the same (proximal) internode was used for dye experiments or flushing experiments (see above). Specific hydraulic conductivity $\left(k_{s}\right)$ describes the permeability of a wood segment for water following Darcy's Law and was calculated as:

$$
k_{s}\left(\mathrm{~m}^{2} \mathrm{~s}^{-1} \mathrm{MPa}^{-1}\right)=Q \times l \times A_{s}^{-1} \times \Delta P^{-1}
$$

where $Q$ is the volume flow rate $\left(\mathrm{m}^{3} \mathrm{~s}^{-1}\right), l$ is the length of the segment (m), $A_{s}$ is the sapwood cross-sectional area $\left(\mathrm{m}^{2}\right)$, and $\Delta P$ is the pressure difference between the two ends of the segment (MPa). Calculated conductivity data were corrected to $20^{\circ} \mathrm{C}$ to account for changes in fluid viscosity. Conductivity measurements were performed under a hydraulic pressure head of $5.4 \mathrm{kPa}$ with distilled, filtered $(0.22 \mu \mathrm{m})$, and degassed water containing $0.005 \%$ (v/v) Micropur. Samples were weighed after removing superficial water. Afterwards, branch segments were re-cut under water and saturated under vacuum as explained above. Hydraulic conductivity was again measured when the weight of the samples remained constant, which was generally achieved after $96 \mathrm{~h}$. Loss of conductivity (PLCv) was calculated from $k_{s}$ before and after saturation and RWL was calculated as above after drying.

If branches sink in water, their density is $>1 \mathrm{~kg} \mathrm{~L}^{-1}$, but this is no guarantee that all emboli have been removed. We therefore estimated the volume of gas remaining after infiltration as $\mathrm{v}_{\mathrm{gas}}=1-\mathrm{v}_{\mathrm{w}}-\mathrm{v}_{\mathrm{cw}}$, where the proportion of water $\mathrm{v}_{\mathrm{w}}=(\mathrm{SW}-\mathrm{DW}) /$ volume, the proportion of cell walls $\mathrm{v}_{\mathrm{cw}}=\mathrm{DW} / 1.5 /$ volume, 1.5 being the density of cell walls, which is constant across species (Niemz, 1993), and volume was calculated from diameter and length of the debarked sample. Because the basal and distal samples were much longer and less regular in shape, gas content was only calculated for the central section used for PLCV measurements. The remaining gas occupied only $0.8 \pm 6.2 \%$ (mean $\pm \mathrm{SD}, n=134$ ) of the volume and we thus consider that infiltration under vacuum effectively removed the bulk of emboli. Three samples where $v_{\text {gas }}$ was $>11 \%$ were rejected from further comparisons as in these cases the infiltration apparently had not removed all gas. The high standard deviation of $\mathrm{v}_{\text {gas }}$ is most likely the result of inaccuracies in measuring the volume, where a difference of $0.1 \mathrm{~mm}$ in diameter corresponds to a volume difference of about $3.5 \%$, and also because twigs are not the perfect cylinders used to calculate their volume.

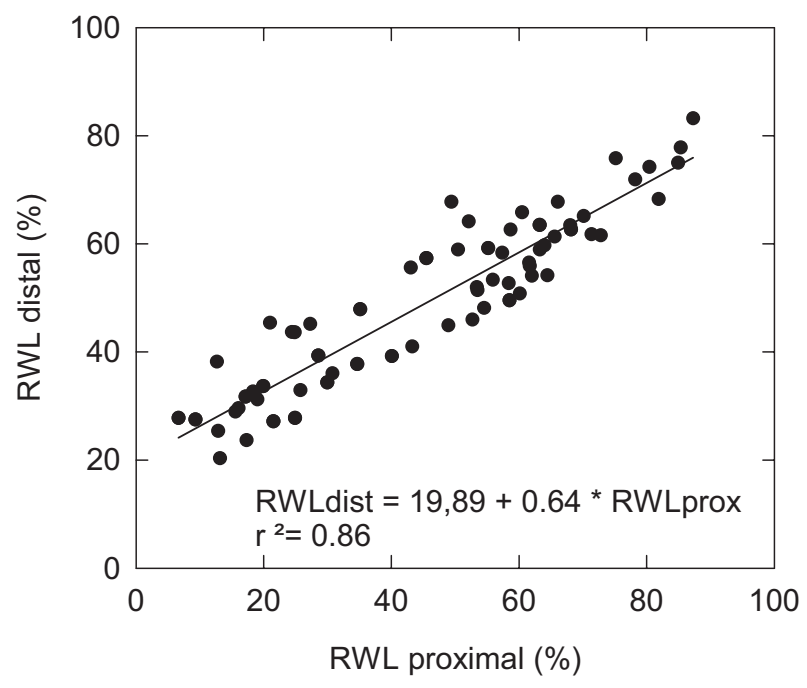

Figure 1. Correlations between relative water loss in the basal and the distal parts of a branch.

\subsection{Percent loss of conductivity by xylem staining (PSX)}

Segments of $5 \mathrm{~cm}$ length were sawed on a band saw and re-cut under water with a microtome blade to a length of $3 \mathrm{~cm}$. Samples were taken from the same internode where PLCV was measured. One third of the debarked branch sample was fitted in a silicone tubing and connected under water to a reservoir of $1 \%$ solution $(\mathrm{w} / \mathrm{v})$ of phloxine B (Sigma Chemical Co., St. Louis, MO, USA), mounted $95 \mathrm{~cm}$ above the outflow end of the sample. This was a slightly higher pressure head than used by previously (Mayr and Cochard, 2003) as preliminary experiments on Norway spruce branch samples showed that even a pressure head of $9.5 \mathrm{kPa}$ did not refill embolised tracheids. When dye solution appeared at the outflow end of the samples, which happened after a few to more than $30 \mathrm{~min}$, depending on RWL, the reservoir was disconnected and the dye was washed from the sample surfaces. After about $20 \mathrm{~min}$ exposure at room temperature, five slices, about $1 \mathrm{~mm}$ thick, were cut from the outflow ends of the branch samples. Cross sections were dried, fixed on paper, and photographed alongside a scale with a Nikon Coolpix 995 digital camera so that the diameter of the cross sections covered about 650 pixels. The part of the pith was removed from the image because it never stained, also in saturated samples, and does not contribute to conductivity. To increase the contrast between stained and unstained xylem, the darkness of the reddish tones was increased and of the yellow/brown tones decreased using the "Replace Color" feature of Photoshop (Photoshop CS 8.0.1, Adobe Systems Inc.). The picture was then converted to grey scales and a threshold was set defining stained and unstained parts, resulting in a picture with only black and white. The stained (black) area of the section was measured with SigmaScan (SigmaScan Pro 5.0.0, SPSS Inc.) and compared with a picture where the area of the entire section minus the pith was measured. Though staining was stronger in some parts and sections than in others (Fig. 3), distinguishing stained xylem was almost always unequivocal and we estimate that the remaining uncertainty does not cover more than a few $\%$ of the area. 

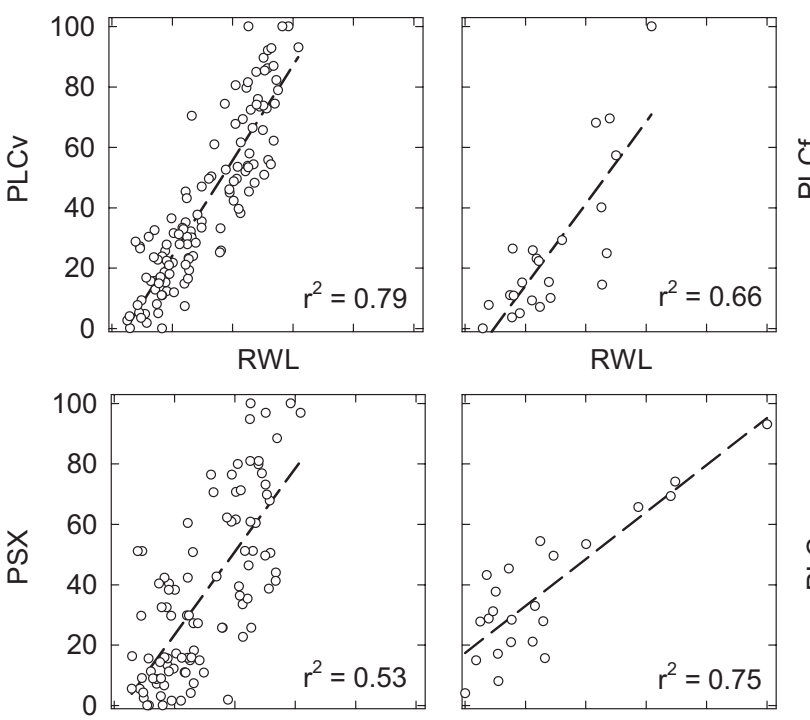

RWL
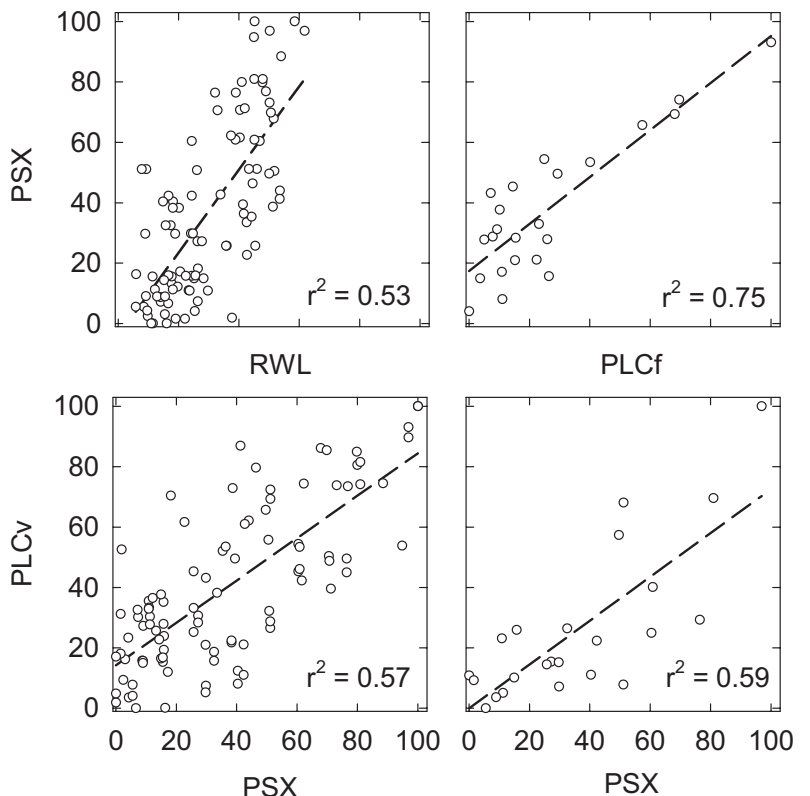

$\vec{d}$

PLCf

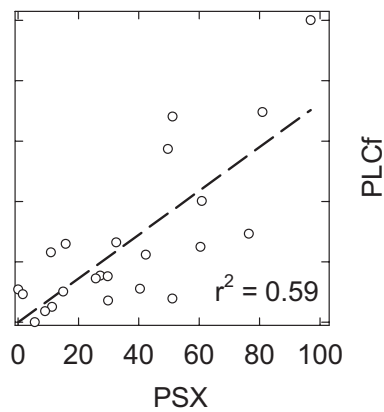

Figure 2. Relationship between relative water loss (RWL), percent loss of conductivity measured via flushing emboli (PLCf), after infiltration under a vacuum (PLCv) and the percent of stained xylem (PSX) in spruce twigs. Pearson $r^{2}$ is given in the graphs, the significance is $p<0.0001$ for all correlations. All scales are $\%$.

\section{RESULTS}

Relative water loss ranged from 6 to $75 \%$ in the proximal sections, from 0 to $62 \%$ in the central sections that were frozen, and from 20 to $76 \%$ in the distal sections of the branch. RWL in the branch sections were highly correlated (Fig. 1), but the slope and offset of the regressions differed significantly ( $p<0.05$, $t$-test) from 1 and 0 , respectively, with RWL on average $5.9 \pm 1.1 \%$ (SE, $n=69$ ) higher in distal than in proximal parts of the twigs. RWL in the central section was lower than in both distal and proximal sections, but this may be related to the fact that this section was cut under water, blotted dry, debarked and infiltrated after freezing. The proportion of gas remaining after infiltration $(0.8 \pm 6.2 \%)$ was not correlated with PLCv (Pearson $r^{2}<0.001, p=0.94$ ), thus greater water loss had not affected the ability to saturate the samples. In the following analysis, measures of conductivity loss are compared to the RWL in the central section, which was the part used for the conductivity measurements.
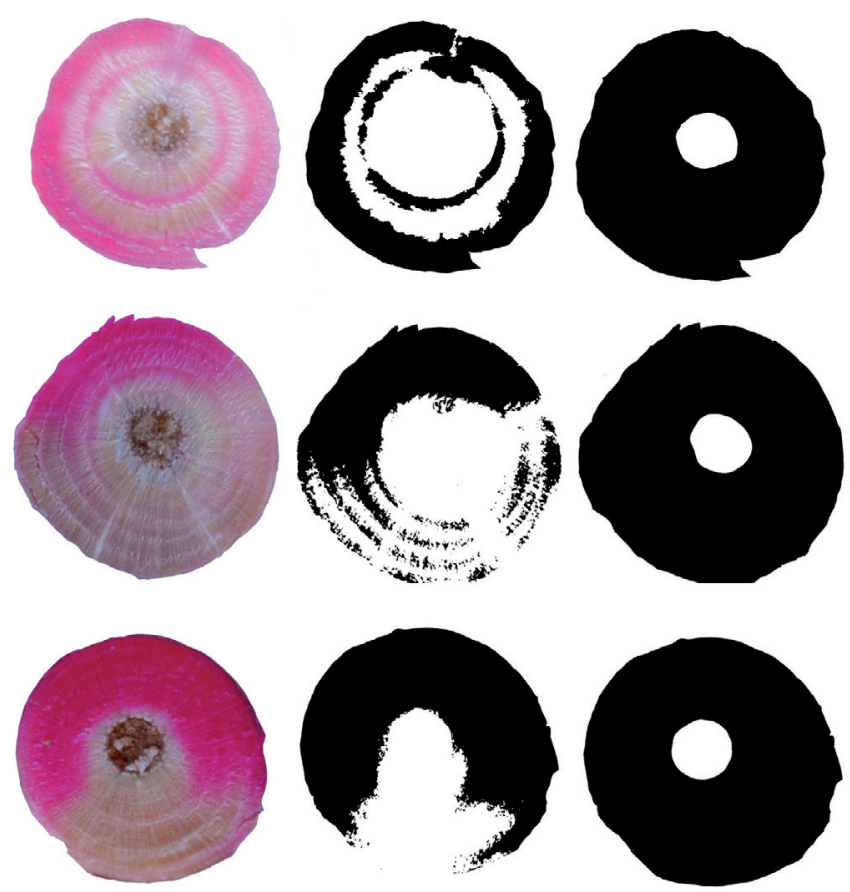

Figure 3. Cross sections of spruce branches stained with phloxine B (left), images obtained by distinguishing stained from unstained wood (centre) and the cross-section minus the pith (right). Percent of stained xylem (PSX) was obtained by dividing the area of the centre by the area of the right hand shapes.

Measurements of PLCv and RWL did not differ in samples stored in a freezer for different time spans. Pearson correlation $r^{2}$ for repeat measurements of PLCv and RWL was 0.79 and 0.76 , respectively, regressions slopes and offsets did not differ significantly from 1 and 0 , respectively, values of repeat measurements did not differ significantly (paired t-test, $p>0.05$ ), and the average difference in PLCv was only $3.1 \%$ (data not shown).

PLCv, PLCf and PSX all ranged between 0 and 100\%, with $100 \%$ loss of conductivity reached when approximately $60 \%$ of the saturation water content had been lost (Fig. 2). All correlations were highly significant (Pearson correlation, $p<0.001$ ) with $r^{2}$ between 0.53 for the correlation between RWL and PSX and 0.81 for the correlation between RWL and PLCv (Tab. I). However, all regressions also differed significantly from an ideal 1:1 relationship with an offset unequal 0 , and in most cases the regression slope was also unequal 1 .

The staining experiment also permitted us to identify the conductive areas within the branch cross-section. Generally, conductivity loss was more common in the inner annual rings, in early wood within an annual ring, and in compression wood, but the pattern differed substantially between branches (Fig. 3).

\section{DISCUSSION}

Flushing twigs with a pressure $>100 \mathrm{kPa}$ is an effective method to remove emboli, but carries a greater risk of pit 
Table I. Correlation coefficient ( $r$ ), offset and slope of linear regressions between different methods (RWL: relative water loss , PLCf: percent loss of conductivity measured via flushing emboli, PLCv: percent loss of conductivity measured via infiltration under a vacuum, and PSX: percent of stained xylem) to quantify loss of hydraulic conductivity. The significance $p$ is the probability for the offset being 0 and the slope of the regression being 1 ( $t$-test).

\begin{tabular}{|c|c|c|c|c|c|c|}
\hline Correlation & $n$ & $r$ & Offset (SE) & $p(=0.0)$ & Slope (SE) & $p(=1.0)$ \\
\hline RWL vs. PSX & 97 & 0.73 & $-4.08(4.41)$ & 0.357 & $1.377(0.133)$ & 0.006 \\
\hline RWL vs. PLCf & 23 & 0.90 & $-12.91(6.84)$ & 0.073 & $1.357(0.212)$ & 0.106 \\
\hline RWL vs. PLCv & 97 & 0.81 & $-7.34(2.53)$ & 0.004 & $1.575(0.076)$ & $<0.001$ \\
\hline PSX vs. PLCv & 123 & 0.77 & $14.22(2.91)$ & $<0.001$ & $0.702(0.063)$ & $<0.001$ \\
\hline PSX vs. PLCf & 23 & 0.75 & $-0.032(5.81)$ & 0.99 & $0.726(0.131)$ & 0.048 \\
\hline PLCf vs. PLCv & 23 & 0.87 & $17.36(3.53)$ & $<0.001$ & $0.778(0.098)$ & 0.034 \\
\hline
\end{tabular}

aspiration and of clogging the cut end than infiltration under a partial vacuum. The latter, however, is far slower and it is not guaranteed that all gas is removed even from thin twigs. Twigs with $4-8 \mathrm{~mm}$ in diameter often took more than $24 \mathrm{~h}$ to sink, and in stem wood with a diameter of $45 \mathrm{~mm}$ gas content could not be reduced below 10\% (Sorz and Hietz, 2006). If the twigs analyzed by Sellin (1991) were not fully saturated after $6 \mathrm{~h}$, this can explain the fact that he found hydraulic conductivity to decline to zero at a higher water content (ca. 70\%) than in our samples. In our experiments, maximum conductivity and the absence of serious clogging was verified by the fact that conductivity was stable after repeated flushing, and near-complete resaturation after infiltration was verified by density measurements, which showed that practically no gas remained in the debarked twigs. The correlation between PLCf and PLCv appeared good at high water loss, but at high water content PLCf was lower than PLCv. If we assume that initial measurements before flushing or infiltration gave the same results, the difference in PLC probably results from different efficiencies in refilling, with lower PLCf suggesting less complete refilling by flushing. This, however, leads to the difficult question how we define maximum in situ conductivity. If even in an unstressed twig parts of the wood (innermost year rings, compression wood, latewood) are air-filled (Gartner et al., 2004) but can become conductive after infiltration, we may obtain exaggerated PLCv. In species with a sizeable pith cavity, the pith could contribute to conductivity after flushing or infiltration, but this was not a problem in spruce as the pith was never stained, not even in infiltrated twigs.

If excessive infiltration is not a problem, this offers an attractive alternative method to flushing, particularly when clogging is a problem. Our experience with spruce is that the key to prevent clogging is to avoid squeezing the twig when cutting, and to make the final cut before conductivity measurements in very clean water and with very sharp blades or knives. This should also remove extruded resin, which can pose an additional problem in many conifers. Irreversibel pit aspiration (see Sect. 1) may be a problem with PLCv and PLCf measurements of samples dehydrated to low water potentials. Since quantifying PSX and RWL does not require conductivity to be restored to pre-stress values, these measures should be unaffected by pit aspiration. The problem of pit aspiration was not topic of our measurements, but warrants further studies.
Relative water content is easily measured and, if samples can be saturated, which can be verified by their density, relative water loss is the measure with the least potential for errors. We found the correlation between RWL and PLC to be about as good as between PLC measured by flushing and infiltration $\left(r^{2}=0.8\right.$ to 0.9 , Tab. I), which makes RWL an alternative measure where the correlation has been verified and quantified. As expected, this correlation is not 1:1 because conductivity is completely lost well before all water is lost. While xylem vulnerability curves relating PLC to water potential generally have a sigmoidal shape with very little loss of conductivity at high water potential, PLCV and PLCf started to increase more or less linearly at a small water loss. Upon drying, the first $5-10 \%$ of water is lost with little effect on PLC, but a further drop in water potential (below -2 to $-3 \mathrm{MPa}$ in spruce; Mayr et al., 2003; Rosner et al., 2006) leads to a stronger increase in PLC than in RWL (Domec and Gartner, 2002; Rosner et al., 2006), which results in the steep increase in the RWL:PLC relationship found.

The correlation will likely be similar in other conifers, but probably not in hardwoods. According to Hagen-Poiseuille's law (Tyree and Zimmermann, 2002) large vessels contribute substantially more to conductivity than their proportion of the cross-sectional area, thus the RWL:PLC correlation may be quite different, depending on which elements are embolized first. In experiments the large vessels when cut will drain first, but this need not be the case in intact wood in situ, resulting in a potential bias in experiments that is difficult to control. Taking RWL as a proxy for PLC is attractive when many repeated measurements are to be made in homogeneous material (similar diameter, even-aged samples, with comparable percentage of the pith), for instance to study seasonal differences.

Staining provides the additional information which parts are conductive (Fig. 3) and is the only method used in this study that does not require resaturation, at least in young twigs where the entire wood will contribute to maximum conductivity in situ. Though there may be some ambiguities in distinguishing weakly stained from unstained tissue, the potential error associated with this appears to be small. The proportion of tissue stained and the color intensity may depend on the time the solution is allowed to percolate through the branch. We found that the coloration of successive slices of wood was almost identical, thus at least short differences in distances and 
Table II. Comparison of advantages and disadvantages of direct and indirect methods to quantify loss of hydraulic conductivity.

\begin{tabular}{lll}
\hline Method & Pros & Cons \\
\hline $\begin{array}{l}\text { Conductivity loss by flushing } \\
\text { (PLCf) }\end{array}$ & $\begin{array}{l}\text { Standard procedure; direct value } \\
\text { for conductivity loss }\end{array}$ & $\begin{array}{l}\text { Tracheids are easily clogged; pit } \\
\text { aspiration }\end{array}$ \\
$\begin{array}{l}\text { Conductivity loss by infiltration } \\
\text { (PLCv) }\end{array}$ & $\begin{array}{l}\text { Direct value for conductivity loss; } \\
\text { infiltration less prone to clogging } \\
\text { and easier handling }\end{array}$ & $\begin{array}{l}\text { Complete saturation needs to be } \\
\text { verified; potential oversaturation; } \\
\text { pit aspiration }\end{array}$ \\
Xylem staining (PSX) & $\begin{array}{l}\text { Allows analysis of different parts; } \\
\text { full saturation not needed; not af- } \\
\text { fected by pit aspiration }\end{array}$ & $\begin{array}{l}\text { Duration of coloration may be crit- } \\
\text { ical; correlation with PLC needed }\end{array}$ \\
Relative water loss (RWL) & Very easy to measure & $\begin{array}{l}\text { Saturation needs to be verified; } \\
\text { correlation with PLC needed }\end{array}$ \\
\hline
\end{tabular}

time did not matter much. Time and size of branches may be more critical in hardwoods, where the dye will cross and therefore stain large vessels much faster than smaller vessels and tracheids. Although water transport in reaction wood and latewood is much slower than in early wood (Spicer and Gartner, 1998; Domec and Gartner, 2002; Mayr and Cochard, 2003), these tissues were perfectly colored in water-saturated twigs, even though the perfusion was stopped shortly after dye appeared on cut surface. The fact that the correlation between PSX and the other measures (PLCv, PLCf and RWL) was not very high (Tab. I) is more likely a result of the measure obtained than of the measurement techniques. Since wood is heterogeneous with earlywood, latewood and compression wood having different hydraulic conductivities (Domec and Gartner, 2002; Mayr and Cochard, 2003), and being stained in different proportions (Fig. 3), a given loss of conducting area does not translate to the same loss of conductivity.

Cation concentrations in the xylem can affect hydraulic conductance by swelling and deswelling pectins in the pit membranes (van Ieperen et al., 2000; Zwieniecki et al., 2001). This could pose a problem for PLC measurements if the ions held by pectins are exchanged as xylem water is replaced by a different solution, which is likely during flushing and infilatration, and in Laurus nobilis PLC measured with pure water was ca. 30\% lower than measurements using $100 \mathrm{mM} \mathrm{KCl} \mathrm{(Gascó}$ et al., 2006). The situation, however, is further complicated by the fact that a low concentration of calcium can counteract a much higher concentration of potassium, and the exchange solution should thus ideally have the same composition as the xylem sap (van Ieperen and van Gelder, 2006). This is difficult to achieve and not (yet) common practice in PLC measurements. Using distilled water could have affected our PLCV and PLCf measurements, though in conifers the effect of cations is smaller than in angiosperms (Zwieniecki et al., 2001). Results of RWL and PSX are not affected by xylem water composition and these methods could usefully serve as reference methods when investigating ion effects.

Advantages, disadvantages and potential problems of the methods compared are summarized in Table II. For physiological questions the relevant measure in most cases will be the loss of conductivity. Only PLC provides a direct measure of the functionality of the hydraulic system, and whether staining or RWL can serve as proxy variables depends on the questions asked. Results of PLC measurements often come with considerable standard deviations, though we found that two measurements of PLCv on the same internode differed by an average of only $3.1 \%$. In most studies experimenters will try to reduce this error as much as possible by selecting the most reliable method and working as diligently as possible. When assessing xylem functionality, the errors or deviations may result from various sources: The measurement per se, i.e., quantifying hydraulic conductivity or distinguishing between stained and unstained sections; procedures necessary to prepare the samples, i.e., refilling emboli, staining wood, and making cuts that do not affect conductivity; and the variation within and between the samples. If emboli can be removed, which the infiltration under low pressure apparently achieved, RWL can be the measure with the lowest potential for errors.

\section{CONCLUSIONS}

Hydraulic methods are the only way to obtain absolute values of conductivity and loss of conductivity, and infiltration under a partial vacuum is a viable and verifiable alternative to flushing. Where correlations with the area of wood stained by perfusion or also relative water loss can be shown, these may serve as proxy variables providing additional information on the distribution of conductive wood or rapid measures, respectively. We caution against using the correlation found in spruce for other species, but would encourage studying other conifers and angiosperms.

Acknowledgements: This study was supported by the "Fonds zur Förderung der Wissenschaftlichen Forschung" (projects P16151B06, P15923-B03 and T304-B16) and by APART (Austrian Programme for Advanced Research and Technology). We thank Birgit Dämon, University Innsbruck for excellent assistance during measurements and two anonymous reviewers for helpful comments.

\section{REFERENCES}

Chiu S.T. and Ewers F.W., 1993. The effect of segment length on conductance measurements in Lonicera fragrantissima. J. Exp. Bot. 44: $175-181$. 
Cochard H., 1992. Use of positive pressures to establish vulnerability curves. Plant Physiol. 100: 205-209.

Cochard H., Bodet C., Améglio T., and Cruiziat P., 2000a. Cryo-scanning electron microscopy observations of vessel content during transpiration in walnut petioles. Facts or artifacts? Plant Physiol. 124: 11911202.

Cochard H., Martin R., Gross P., and Bogeat-Triboulot M.B., 2000b. Temperature effects on hydraulic conductance and water relations of Quercus robur L. J. Exp. Bot. 51: 1255-1259.

Cochard H., Lemoine D., Améglio T., and Granier A., 2001. Mechanisms of xylem recovery from winter embolism in Fagus sylvatica. Tree Physiol. 21: 27-33.

Cochard H., Froux F., Mayr S., and Coutand C., 2004. Xylem wall collapse in water-stressed pine needles. Plant Physiol. 134: 401-408.

Cochard H., Damour G., Bodet C., Tharwat I., Poirier M., and Ameglio T., 2005. Evaluation of a new centrifuge technique for rapid generation of xylem vulnerability curves. Physiol. Plant. 124: 410-418.

Domec J.C. and Gartner B.L., 2002. Age- and position-related changes in hydraulic versus mechanical dysfunction of xylem: inferring the design criteria for Douglas-fir wood structure. Tree Physiol. 22: 91104.

Gartner B.L., Moore J.R., and Gardiner B.A., 2004. Gas in stems: abundance and potential consequences for tree biomechanics. Tree Physiol. 24: 1239-1250.

Gascó A., Nardini A., Gortan E., and Salleo E., 2006. Ion-mediated increase in the hydraulic conductivity of Laurel stems: role of pits and consequences for the impact of cavitation on water transport. Plant Cell Environ. 29: 1946-1955.

Hacke U.G. and Sperry J.S., 2001. Functional and ecological xylem anatomy. Perspectives in Plant Ecology, Evolution and Systematics 4: 97-115.

Hacke U.G., Sperry J.S., and Pittermann J., 2004. Analysis of circular bordered pit function II. Gymnosperm tracheids with torus-margo pit membranes. Am. J. Bot. 91: 369-385.

Hansmann C., Gindl W., Wimmer R., and Teischinger A., 2002. Permeability of wood. Wood Res. 47: 1-16.

Kikuta S.B., Hietz P., and Richter H., 2003. Vulnerability curves from conifer sapwood sections exposed over solutions with known water potentials. J. Exp. Bot. 54: 2149-2155.

Lo Gullo M.A. and Salleo S., 1991. Three different methods for measuring xylem cavitation and embolism: a comparison. Ann Bot 67: 417-424.

Mayr S. and Cochard H., 2003. A new method for vulnerability analysis of small xylem areas reveals that compression wood of Norway spruce has lower hydraulic safety than opposite wood. Plant Cell Environ. 26: 1365-1371.

Mayr S., Rothart B., and Dämon B., 2003. Hydraulic efficiency and safety of leader shoots and twigs in Norway spruce growing at the alpine timberline. J. Exp. Bot. 54: 2563-2568.
Mayr S., Wolfschwenger M., and Bauer H., 2002. Winter-drought induced embolism in Norway spruce (Picea abies) at the Alpine timberline. Physiol. Plant. 115: 74-80.

Mayr S., Rothart B., and Wolfschwenger M., 2006. Temporal and spatial pattern of embolism induced by pressure collar techniques in twigs of Picea abies. J. Exp. Bot. 57: 3157-3163.

Niemz P., 1993. Physik des Holzes und der Holzwerkstoffe, DRW-Verlag, Leinfelden, Germany, 243 p.

Petty J.A., 1972. The aspiration of bordered pits in conifer wood. Proc. R. Soc. Lond., B, Biol. Sci. 181: 395-406.

Rosner S., Klein A., Wimmer R., and Karlsson B., 2006. Extraction of features from ultrasound acoustic emissions: a tool to assess the hydraulic vulnerability of Norway spruce trunkwood? New Phytol. 171: $105-116$.

Salleo S., Lo Gullo M.A., de Paoli D., and Zippo M., 1996. Xylem recovery from cavitation-induced embolism in young plants of Laurus nobilis: a possible mechanism. New Phytol. 132: 47-56.

Sellin A., 1991. Hydraulic conductivity of xylem depending on water saturation level in Norway spruce (Picea Abies (L.) Karst.). J. Plant Physiol. 138: 466-469.

Sorz J. and Hietz P., 2006. Gas diffusion through wood: implications for oxygen supply. Trees 20: 34-41.

Sperry J.S., 1986. Relationship of xylem embolism to xylem pressure potential, stomatal closure, and shoot morphology in the palm Rhapis excelsa. Plant Physiol. 80: 110-116.

Sperry J.S. and Tyree M.T., 1990. Water-stress-induced xylem embolism in three species of conifers. Plant Cell Environ. 13: 427-436.

Sperry J.S., Donnelly J.R., and Tyree M.T., 1988. A method for measuring hydraulic conductivity and embolism in xylem. Plant Cell Environ. 11: 35-40.

Sperry J.S., Nichols K.L., Sullivan J.E.M., and Eastlack S.E., 1994. Xylem embolism in ring-porous diffuse-porous, and coniferous trees of northern Utah and interior Alaska. Ecology 75: 1736-1752.

Spicer R. and Gartner B.L., 1998. Hydraulic properties of Douglas-fir (Pseudotsuga menziesii) branches and branch halves with reference to compression wood. Tree Physiol. 18: 777-784.

Tyree M.T. and Zimmermann M.H., 2002. Xylem structure and the ascent of sap, Springer, Berlin, 283 p.

Van Ieperen W., van Meeteren U., and van Gelder H., 2000. Fluid ionic composition influences hydraulic conductance of xylem conduits. J. Exp. Bot. 51: 769-776.

Van Ieperen W. and van Gelder A., 2006. Ion-mediated flow changes suppressed by minimal calcium presence in xylem sap in Chrysanthemum and Prunus laurocerasus. J. Exp. Bot. 57: 27432750.

Vogt U.K., 2001. Hydraulic vulnerability, vessel refilling, and seasonal courses of stem water potential of Sorbus aucuparia L. and Sambucus nigra L. J. Exp. Bot. 52: 1527-1536.

Zwieniecki M.A., Melcher P.J., and Holbrook N.M., 2001. Hydrogel control of xylem hydraulic resistance in plants. Science 291: 1059-1062. 